\title{
Erratum to: Note to: a mathematical model and ant colony algorithm for multi-manned assembly line balancing problem
}

\author{
Hamid Yilmaz ${ }^{1}$ Mustafa Yilmaz ${ }^{1}$
}

Published online: 1 October 2016

(C) Springer-Verlag London 2016

Erratum to: Int J Adv Manuf Technol

DOI 10.1007/s00170-016-9223-y

The name of one author was omitted in the initially published version. The complete list of authors is presented in this paper and the original article was corrected.

The online version of the original article can be found at doi:10.1007 /s00170-016-9223-y.

Hamid Yilmaz

hamidyilmaz@gmail.com

1 Ataturk Universitesi, Erzurum, Turkey 